male and female participants in different team field sports could not be missed.

5. The point of view defended by us, that the functional load of women and men is nearly the same, at least according to the relation of the heart rate and the maximum frequency, will not say that the man is not doing more physical labour during the match than the woman. This can, as everybody knows, never be expected because of the big differences in physical capacities between both sexes. So we are seeing quite clearly a division of work; part of the tactics of the "korfbal" match.

6. However this means according to us that conditioning training of women and men must be always separated because giving the same instructions to both sexes gives a possibility of underloading the men and overloading the women, which makes the results of this training at least doubtful.

7. Once again we emphasize the high average heart rate (nearly 200) of our first female subject. When one follows this train of thoughts this means that this woman loaded her heart heavily by participating in this "micro-korfbal" match in spite of, or perhaps thanks to, the fact that she did not belong to the top class players. This would give according to me an indication that the demands in a medical examination for competitive sport may be independent of the class in which one plays. Perhaps the opposite could be concluded from this single observation.

\title{
POSTURAL TRAINING IN ATHLETES
}

W. E. TUCKER, F.R.C.S.

71 Park Street, London, W.1

\section{ABSTRACT}

The prevention of athletic injuries and their recurrences should be an essential part of athletic training. In the comprehensive treatment of athletic injuries, treatment by a team of experts is essential. Each member should be so well trained in his particular branch, that the athlete should receive first-class treatment at every stage. There must be efficient first-aid treatment. After an exact diagnosis using all the available ancillary methods, the surgeon details his 6 recommendations. Operation may be necessary. The nature of his injury is explained to the athlete, and it must be stressed to him that he can contribute greatly to his recovery by conscientious and regular self-treatment at home. The physiotherapist is called in to help almost immediately. In due course, the injured athlete is referred to the trainer with exact instructions.

Many athletic injuries occur and recur because the athlete has not been taught the essentials of body mechanics.

The individual, however, can decide whether the way he carries himself in the upright position is one of Active Alerted, Balanced Posture; or the opposite, an inactive unbalanced slumping one. Posture therefore in the upright position is entirely an individual attitude of mind.

A failure to appreciate the importance of correct posture allows a gravity strain on the lower fixed parts - and may predispose towards fibrosity, myalgia, joint strain progressing to arthritis, metatarsalgia, subluxation of the hip, prolonged intavertebral disc, abdominal herniae and cervical spondylosis.

NOTE

For a full description, the reader is referred to Mr. W. E. Tucker's monograph "Active Alerted Posture" (1960) Published by E. and S. Livingstone - Edinburgh.

\section{DISABILITIES OF THE ELBOW JOINT}

\section{W. E. TUCKER, F.R.C.S.}

The structure of the joint was described, and its dislocations and injuries to the surrounding muscles are described.

The full text was published in the British Journal of Sports Medicine, Vol. VI, 69-75, 1972 